\title{
Stable doped hybrid sol-gel materials for solid-state dye laser
}

\author{
Tran H. Nhung, Michael Canva, Truong T. A. Dao, Frédéric Chaput, Alain Brun, \\ Nguyen D. Hung, and Jean-Pierre Boilot
}

\begin{abstract}
Laser effects have been obtained with dye-doped hybrid xerogel samples prepared several years ago and stored in different "classical" conditions. Firstly, using the same configuration of the laser cavity as was used 4-5 years ago, we have obtained almost identical laser performances, and slope conversion efficiencies were measured up to $80 \%$ and operational lifetimes, with 1-mJ initial output energy and $10-\mathrm{Hz}$ repetition rate of several hundred thousand pulses obtained. Secondly, we have introduced the new pyrromethene 605 dye into a hybrid xerogel matrix and obtained good laser performances similar to the rest of the pyrromethene family. (C) 2003 Optical Society of America

OCIS codes: $160.6060,160.4890,140.2050,140.3600,160.3380,140.3580$.
\end{abstract}

\section{Introduction}

Much research has already been devoted to solidstate dye lasers, because of their high laser efficiency and their technical and economical advantages. ${ }^{1-8}$ Many different materials have been used as a solid host for organic dyes, such as methylmethacrylate based polymers, ${ }^{2,9-14}$ sol-gel glasses, ${ }^{3,15}$ polycom glasses, ${ }^{16,17}$ hybrid materials, $, 5,18-24$ and epoxy resins. ${ }^{22}$ The key parameters concerning these materials are laser efficiency and photodegradation rate or lifetime. Recently, the most promising results have been obtained mainly with the pyrromethene-doped sol-gel hybrid materials.7,14 For these materials, slope efficiencies up to $50-86 \%$ and lifetimes of several

T. H. Nhung, M. Canva (michael.canva@iota.u-psud.fr), Tr. T. A. Dao, and A. Brun are with the Groupe d'Optique Non-Linéaire, Laboratoire Charles Fabry de l'Institut d'Optique, Centre National de la Recherche Scientifique, UMR 8501, Bâtiment 503, 91403 Orsay Cedex, France. F. Chaput and J.-P. Boilot are with the Groupe de Chimie du Solide, Laboratoire de Physique de la Matière Condensée, École Polytechnique, Centre National de la Recherche Scientifique, URA D-1254, 91128 Palaiseau Cedex, France. N. D. Hung is with the Laboratory of Photomolecular Physics, Institute of Physics, National Center for Sciences and Technology (CNST), Nghia do, Cau giay, Hanoi, Vietnam. T. H. Nhung and Tr. T. A. Dao are currently on leave from Institute of Physics, National Center for Sciences and Technology, Nghia do, Cau giay, Hanoi, Vietnam.

Received 31 July 2002; revised manuscript received 26 November 2002 .

0003-6935/03/122213-06\$15.00/0

(C) 2003 Optical Society of America hundred thousands pulses with 1-mJ initial energy output at $10 \mathrm{~Hz}$ of repetition rate have been obtained. In particular, the oxygen-free pyrromethene-doped samples have a lifetime of $10^{6}$ pulses. $^{7}$ It has been shown that the pyrromethene dyes have higher laser efficiency and operational photostability in comparison with the other dye families, like rhodamine or perylene. With advantages such as high energy conversion, high lifetime, and thermal stability, the pyrromethene dyes are currently the most promising dyes used for solid-state laser performances. This is shown by the increase in the number of published works on pyrromethene dyes, especially 567, for solidstate lasers ${ }^{7,12,14,17-19,23-33}$ in recent years. Table 1 summarizes some of the pyrromethene data in solution and in our hybrid solid sol-gel matrix. There are currently seven commercially available pyrromethene (PM) dyes in catalogues (Exciton and Lambda-Physik): $546,556,567,580,597,605$, and 650 . It is clear that the pyrromethene dye laser emissions cover the visible green-red wavelength range. As mentioned most of the published data is devoted to PM 567, as the PM 546 and PM 556 are not suited for the important 532-nm doubled-frequency Nd:YAG laser optical pumping, and therefore PM 567 corresponds to minimum wavelength shift during the dye laser emission process and thus minimum loss of energy for equal quantum conversion efficiency. Until now, only PM 567, 580, and 597 results have been well investigated.

In this communication, we report (for the first time, to our knowledge) the laser characterizations of solgel hybrid dye-doped samples after many years of storage in order to assess the chemical stability of our 
Table 1. Pyrromethene Dye Data ${ }^{a}$

\begin{tabular}{|c|c|c|c|c|c|c|c|c|c|}
\hline \multirow[b]{3}{*}{$\begin{array}{c}\text { Pyrromethene } \\
\text { Dye }\end{array}$} & \multicolumn{2}{|c|}{$\lambda_{\mathrm{Abs}}{ }^{e}$} & \multicolumn{2}{|c|}{$\lambda_{\text {Fluo }}{ }^{e}$} & \multicolumn{2}{|c|}{$\lambda_{\text {Laser }}^{e}$} & \multicolumn{3}{|c|}{ Tunability $^{e}$} \\
\hline & \multirow[b]{2}{*}{$\underset{\text { Solution }}{\text { In }}$} & \multirow{2}{*}{$\begin{array}{c}\text { In } \\
\text { Solid } \\
\text { Hybrid } \\
\text { Matrix }\end{array}$} & \multirow[b]{2}{*}{$\begin{array}{c}\text { In } \\
\text { Solution }\end{array}$} & \multirow{2}{*}{$\begin{array}{c}\text { In } \\
\text { Solid } \\
\text { Hybrid } \\
\text { Matrix }\end{array}$} & \multirow[b]{2}{*}{$\begin{array}{c}\text { In } \\
\text { Solution } \\
\text { (ethanol) }\end{array}$} & \multirow{2}{*}{$\begin{array}{c}\text { In } \\
\text { Solid } \\
\text { hybrid } \\
\text { matrix }\end{array}$} & \multicolumn{2}{|c|}{$\begin{array}{c}\text { Nd:YAG excitation at } \\
532 \mathrm{~nm} \\
\end{array}$} & $\begin{array}{c}\text { Flash } \\
\text { excitation }\end{array}$ \\
\hline & & & & & & & $\begin{array}{l}\text { In solid } \\
\text { hybrid } \\
\text { matrix }\end{array}$ & $\begin{array}{c}\text { In } \\
\text { solution }\end{array}$ & $\begin{array}{c}\text { In } \\
\text { solution }\end{array}$ \\
\hline PM 546 & 494 & & 519 & & $546^{b}$ & n. ap. & n. ap. & n. ap. & $523-584$ \\
\hline PM 556 & 498 & & 533 & & $561^{b}$ & n. ap. & n. ap. & n. ap. & $537-605$ \\
\hline PM 567 & 518 & $520^{d}$ & 547 & $545^{c, d}$ & $567^{b}$ & $560^{c, d}$ & $545-585^{d}$ & 549-592 & $537-560$ \\
\hline PM 580 & 519 & $522^{d}$ & 550 & $548^{c, d}$ & $580^{b}$ & $568^{c, d}$ & $545-595^{d}$ & $545-585$ & $550-590$ \\
\hline PM 597 & 524 & $525^{d}$ & 557 & $570^{c, d}$ & $593^{b}$ & $588^{c, d}$ & $572-612^{d}$ & $560-600$ & $570-620$ \\
\hline PM 605 & 545 & $543^{d}$ & 582 & $579^{c, d}$ & & $590^{c, d}$ & $585-625^{d}$ & & $590-620$ \\
\hline PM 650 & 590 & & 612 & & $630^{c}$ & & study & $604-630$ & \\
\hline
\end{tabular}

${ }^{a}$ Absorption and fluorescence and laser data in solution are from the Lambda Physik laser dye catalogue. Tunability data in solution (with both Nd:YAG and flash excitation) are from Laser Wavelength, Exciton, Inc. All absorption, fluorescence, laser, and tunability data in solid hybrid matrix are our data. n. ap. stands for not applicable in the case of "blue" dye not suitable for optical pumping at $532 \mathrm{~nm}$.

${ }^{b}$ with flashlamp excitation.

${ }^{c}$ with laser Nd:YAG excitation at $532 \mathrm{~nm}$

${ }^{d}$ Our results

${ }^{e}$ in nanometers

materials with time. This is a prerequisite for future application outside the laboratory. We also extend the data concerning the pyrromethene dyes to the PM 605 studied in similar conditions to the other members of the family (work on PM 650 is also being carried out and will be published separately, as its chemical structure is different and its behavior different from the rest of the family).

\section{Experimental Method and Results}

\section{A. Aging of Dye Doped Hybrid Sol-Gel Materials}

The samples under investigation reported in this section are pyrromethene (567, 580, and 597), perylene (orange and red) and rhodamine (B) doped matrices prepared between 1995 and 1996 whose initial performances as gain media of solid-state lasers were reported previously. ${ }^{7}$ The samples were stored either under nitrogen atmosphere or in normal ambient air; some were stored in a dry environment, others in a humid one, most of them in absence of light.

To study the samples, we used the same configuration of the laser cavity as before, depicted in Fig. 1 and reported in our previous paper, ${ }^{7}$ i.e., a $10-\mathrm{cm}$-long stable plano-concave linear cavity. The concave mirror, with a $10-\mathrm{m}$ radius of curvature, is dichroic, with $T_{\text {in }}=80 \%$ at $532 \mathrm{~nm}$, and $R_{\text {in }}>80 \%$ in the $550-650 \mathrm{~nm}$ range. The flat output coupler transmits $90 \%$ energy in the 550-650 $\mathrm{nm}$ range. The excitation laser is a frequency-doubled Nd:YAG emitting 6-ns pulse FWHM at a 532-nm wavelength; its repetition rate may be varied between a single shot and $10 \mathrm{~Hz}$.

We measured the slope efficiency of samples stored under various conditions, immediately after they were taken from storage and, for those stored under special conditions, also after several days, in order to observe the influence that such factors as oxygen diffusion have on the samples. It appeared that, for all samples, the slope efficiencies were not affected with time, independently of their storing conditions. For example, we can see in Fig. 2 the case of a PM 567 sample characterized several weeks and several years after synthesis. All the results of slope efficiency measurements obtained for perylene orange, perylene red, rhodamine B (Rh B), PM 567, PM 580, and PM 597 are reported in Table 2. The data all correspond to single-shot use of the pump laser.

The other most important laser parameter is its operational lifetime, defined as the number of pulses that may be emitted before output energy reaches half of its initial value. With a repetition rate of 10 $\mathrm{Hz}$ and using a pump energy of $1 \mathrm{~mJ}$, we obtained, within the data approximation, the same results for the pyrromethene-, perylene-, and rhodamine B-doped samples, as those measured $4-5$ years ago.

As already demonstrated in Ref. 7, in the particular

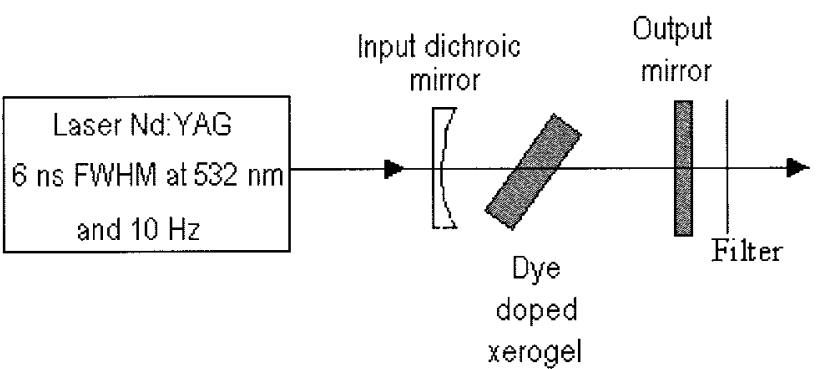

Fig. 1. Configuration of the laser cavity. The cavity is linear, 10 $\mathrm{cm}$ long, and plano-concave. The input mirror is dichroic with a $10-\mathrm{m}$ radius, $T_{\text {in }}=80 \%$ at $532 \mathrm{~nm}$, and $R_{\text {in }}>80 \%$ in the $550-$ 650 -nm range. The flat output coupler has $T_{\text {out }}=90 \%$ in the $550-650-\mathrm{nm}$ range. The Nd:YAG laser delivers pulse with 6-ns FWHM at $532 \mathrm{~nm}$ and $10 \mathrm{~Hz}$. 


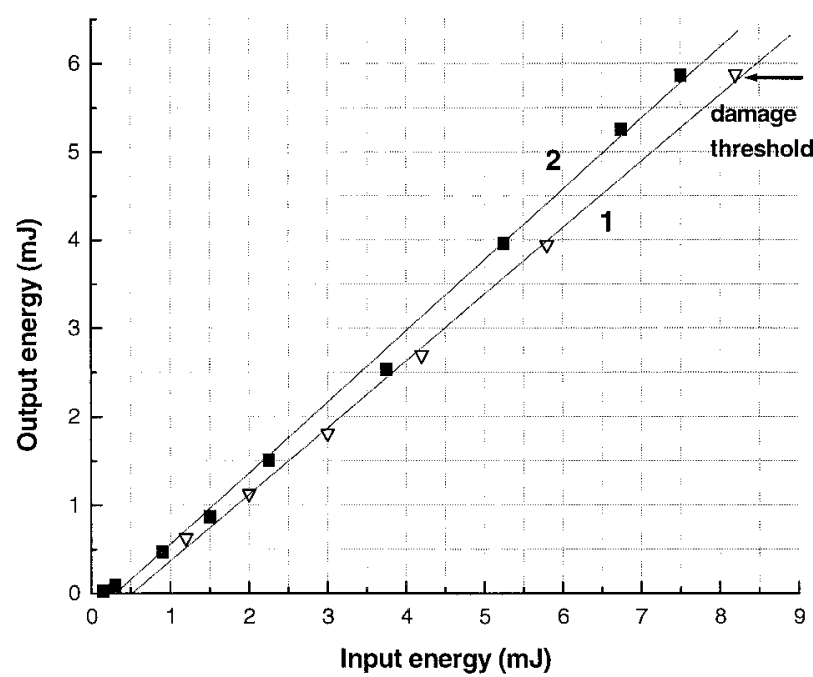

Fig. 2. Laser conversion efficiency of a PM 567 doped sample prepared in April 1996. (1) conversion efficiency of 76\% as obtained in 1996, (2) conversion efficiency of $80 \%$ as obtained in 2001. The damage threshold is almost the same: input energy of $\sim 8$ $\mathrm{mJ}$.

case of the pyrromethene-doped samples (PM 567, PM 580, and PM 597), we observe that the operational lifetime is not affected by pumping repetition rate when varied in the $0.2-10 \mathrm{~Hz}$ range, indicating the absence of nonlinear thermally induced extra degradation for these molecules.

With these samples, we also used more powerful input pulse energy in order to start the measurements with laser output energy of $1 \mathrm{~mJ}$ for the same samples (repetition rate, $10 \mathrm{~Hz}$ ). For example, the upper portion of Fig. 3 shows a lifetime of about $2 \times$ $10^{5}$ pulses for a PM 597-doped xerogel sample $(5.5 \times$ $10^{-4} \mathrm{~mol} / \mathrm{l}$ concentration; 1 -cm thickness) stored for 5 years. For all of the pyrromethene-doped samples studied in these conditions, we measured lifetimes of several hundred thousand pulses (shown in Table 3).

We also repeated the procedure, degassing a sample under vacuum and placing it in a sealed cell. With such "oxygen free and protected" PM 597-doped sample, the slope conversion efficiency was not affected and the operational lifetime was increased 5 -fold from $2 \times 10^{5}$ to above $10^{6}$ pulses (lower portion of Fig. 3).

Table 2. Laser Conversion Efficiency of Dye Doped Hybrid Xerogel Samples Prepared in 1995 and 1996; Measurements Were Made in 1996 and at the Beginning of $2001^{a}$

\begin{tabular}{ccccccc}
\hline $\begin{array}{c}\text { Dye and Slope } \\
\text { efficiency (\%) }\end{array}$ & PO & PR & $\begin{array}{c}\text { PM } \\
567\end{array}$ & $\begin{array}{c}\text { PM } \\
580\end{array}$ & $\begin{array}{c}\text { PM } \\
597\end{array}$ & RhB \\
\hline 1996 & 52 & 12 & 76 & 71 & 60 & 30 \\
2001 & 55 & 13 & 80 & 70 & 55 & 31 \\
\hline
\end{tabular}

${ }^{a}$ Concentration of perylene orange $(\mathrm{PO})$ and rhodamine $\mathrm{B}(\mathrm{RhB})$ is $2 \times 10^{-4} \mathrm{~mol} / \mathrm{l}$; concentration of perylene red (PR), PM 567, PM 580 , and PM 597 is $5.5 \times 10^{-4} \mathrm{~mol} / \mathrm{l}$. The measurements have an error bar estimated at a few percent. All of the results are obtained with a single-shot use of the pump laser.
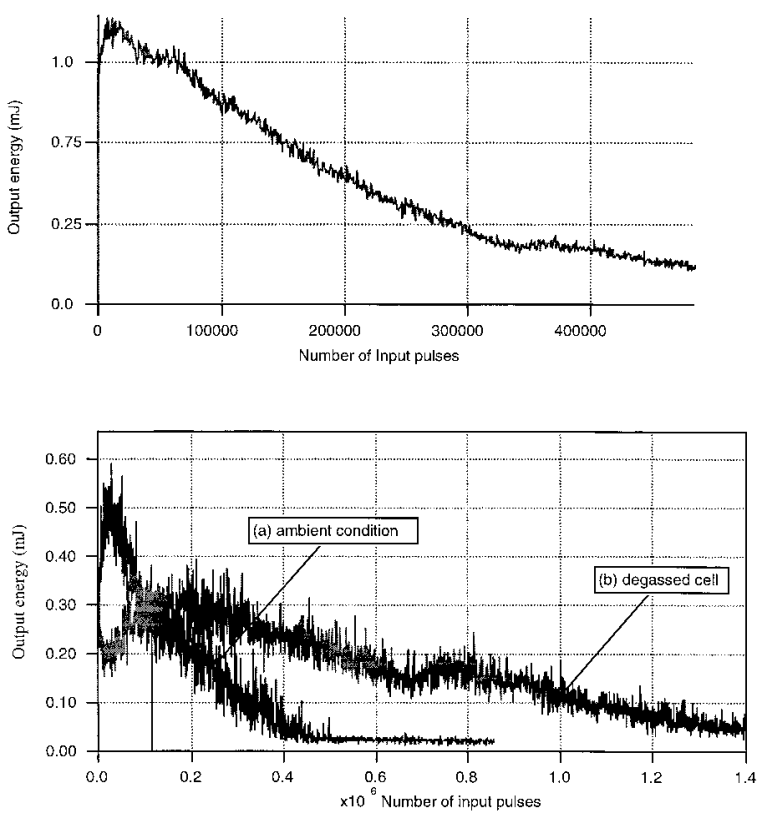

Fig. 3. Output energy evolution as a function of a previously emitted pulse. The xerogel sample was doped with pyrromethene 597 (5.5 $\times 10^{-4} \mathrm{~mol} / \mathrm{l}$ concentration; 1-cm thickness); the laser was operated at $10 \mathrm{~Hz}$. Upper figure, initial output energy is $1 \mathrm{~mJ} /$ pulse; lower figure, (a) sample in classical conditions and (b) sample degassed and sealed under vacuum in a cell.

These results indicate that such xerogel organomineral host matrices doped with organic chromophores are chemically stable. Their properties, as measured by their use as efficient gain media of solid-state dye lasers, remain unchanged over periods of several years ( $>5$ years). This may be due to the fact that the solid matrix is composed of a threedimensional inorganic network of siloxane bridges ( $\mathrm{Si}-\mathrm{O}-\mathrm{Si}$ ) with covalently bonded methyl- $\mathrm{CH}_{3}$ groups, the chromophores being inserted in this network. The organic methyl group provides the organic dye with the necessary environment for efficient fluorescence emission, i.e., weak electron-phonon coupling. The rigid-lattice inorganic network protects the dyes from impurities, in particular preventing oxygen attack over time. Practically speaking, the hybrid matrix provides an almost ideal microscale local environment for the dye molecules trapped within the pore. Further physicochemical investigations of doped matrix aging, however, are necessary in order to better understand eventual aging mechanisms.

\begin{tabular}{|c|c|c|c|}
\hline $\begin{array}{c}\text { Lifetime } \\
\left(\times 10^{3} \text { pulses }\right)\end{array}$ & PM 567 & PM 580 & PM 597 \\
\hline 1996 & 190 & 300 & 190 \\
\hline 2001 & 180 & 260 & 210 \\
\hline
\end{tabular}

Table 3. Lifetimes $\left(E_{\text {laserout }}>1 / 2 E_{\text {outinitial }}\right)$ of Three Pyrromethene Doped Samples, $c=5.5 \times 10^{-4} \mathrm{~mol} / \mathrm{l}$. Operation Conditions: 


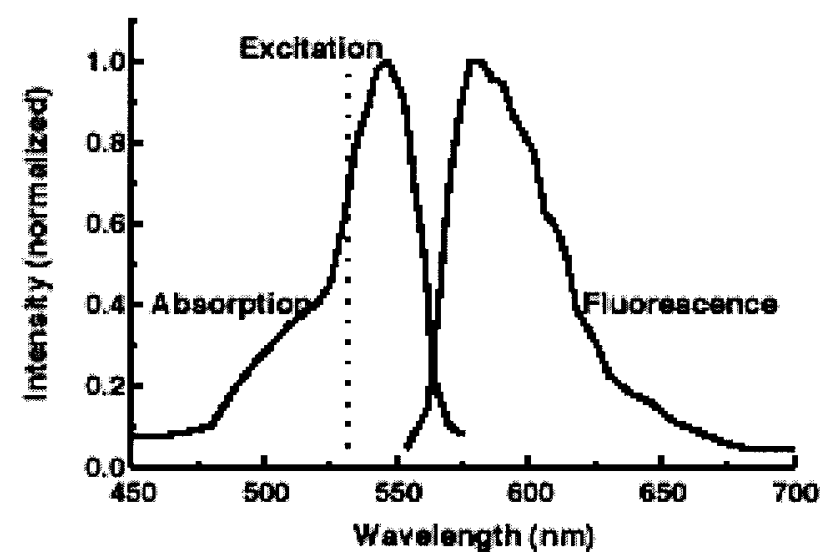

Fig. 4. Absorption and fluorescence (when excited at $532 \mathrm{~nm}$ ) spectra of the new PM 605 doped sol-gel materials (sample has a concentration of $10^{-4} \mathrm{~mol} / \mathrm{l}$ and a thickness of $1 \mathrm{~cm}$ ).

\section{B. Laser Performance of Pyrromethene 605 Doped Hybrid Solid Matrix}

The second novel result in this communication concerns the introduction of PM 605 into hybrid sol-gel material. The method for general synthesis of hybrid xerogel materials is identical to the other chromophore doped systems we have reported on, and has been previously described. ${ }^{7}$ Sol-gel materials doped with PM 605 were prepared from a organically modified precursor (specifically, methyltriethoxysilane). Hydrolysis of the silicon alkoxides was performed under acidic conditions with acetone as the common solvent. After several hours of hydrolysis at room temperature, a small amount of amine-modified silane (3-triethoxysilylpropylamine) was added to neutralize the acidity of the medium, thereby increasing the polymerization reaction rate. The acetonic solution of PM 605 (Exciton, Inc) was then added to yield a concentration in the range from $10^{-5}$ to $5.5 \times 10^{-4}$ $\mathrm{mol} / \mathrm{l}$. Such sol-gel protocol has been monitored using NMR ${ }^{29} \mathrm{Si}$ signal. Dried samples are finally cut and polished to optical quality (about nanometer roughness rms). Typical absorption and fluorescence spectra of such material are presented in Fig. 4.

The laser characterization of PM 605-doped samples was measured with the same laser cavity configuration as described above (Fig. 1). Figure 5 represents the laser conversion efficiency obtained in 2001 of PM 605-doped sample prepared 5 years ago. Figure 6 shows the output energy evolution of one PM 605 xerogel-doped sample with pumping conditions of $1 \mathrm{~mJ} /$ pulse at $10 \mathrm{~Hz}$; the lifetime is close to $2 \times 10^{5}$ pulses. The results of laser conversion and operational lifetime (for initial output energy of $1 \mathrm{~mJ} /$ pulse at $10-\mathrm{Hz}$ repetition rate) as a function of dye concentration are presented in Table 4 . The best slope efficiency of $68 \%$ is achieved with a concentration of $2 \times$ $10^{-5} \mathrm{~mol} / \mathrm{l}$, and the best lifetime of $1 \times 10^{5}$ pulses is obtained for the highest sample concentration of $5.5 \times 10^{-4} \mathrm{~mol} / \mathrm{l}$. As already known, the best lifetimes are effectively obtained with overconcentrated samples with respect to conversion efficiency. As in

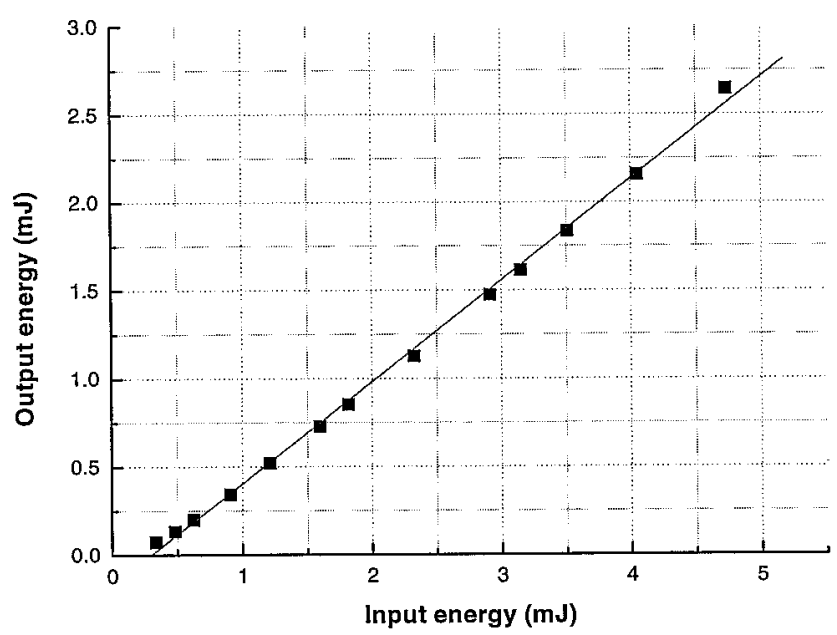

Fig. 5. Laser conversion efficiency of PM 605 doped sample: $57 \%$ for $c=2 \times 10^{-4} \mathrm{~mol} / \mathrm{l}$.

the case of the other pyrromethenes $(567,580$, and 597), the operational lifetime of PM 605-doped samples are not affected by the repetition rate in range from 0.2 to $10 \mathrm{~Hz}$. The tunability achieved with a diffraction grating in Littrow configuration is linked to the large fluorescent band of the dye molecules; we obtained 585-625 $\mathrm{nm}$ for sample concentration of $2 \times$ $10^{-4} \mathrm{~mol} / \mathrm{l}$, pumped at an energy of about $1 \mathrm{~mJ}$, typically 3 times above threshold. Such data, although not reported at the time, had been obtained shortly after their synthesis and confirmed recently as for the other samples reported in the preceding section. It can be noted that the PM 605 dye is the most efficient pyrromethene dye we have tested so far on the red edge of the spectral band covered by this family. However, on the blue side of PM 605, PM597 would be preferred.

\section{Conclusion}

Results of dye-doped sol-gel materials used as gain media of laser systems, studied both shortly after material synthesis and after several years of storage in different conditions, demonstrate the excellent chemical stability of these materials. The data show

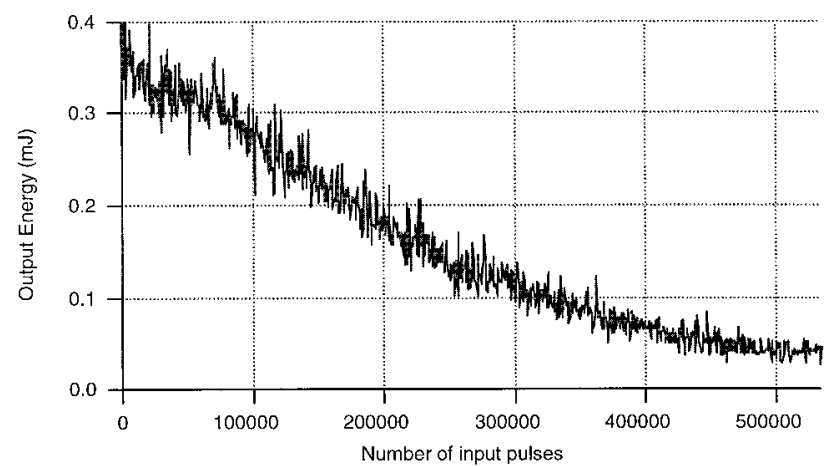

Fig. 6. Output energy evolution of the laser with a PM 605 doped sample prepared in 1996; the measurement was made in 2001. The pumping condition was $1 \mathrm{~mJ} /$ pulse at $10 \mathrm{~Hz}$. 
Table 4. Laser Characteristics of PM 605 Doped Xerogel Samples as a Function of Dye Concentration ${ }^{a}$

\begin{tabular}{lcccrrr}
\hline Concentration $\left(\times 10^{-4} \mathrm{~mol} / \mathrm{l}\right)$ & 0.1 & 0.2 & 0.55 & 1 & 2 & 5.5 \\
Slope efficiency $(\%)$ & 24 & 68 & 63 & 60 & 57 & 58 \\
Lifetime (in $10^{3}$ number of pulses) & $<0.1$ & 4 & 11 & 52 & 98 \\
\hline
\end{tabular}

${ }^{a}$ The laser conversion efficiency corresponds to a single-shot operation of the laser system. The lifetime was measured with an initial output energy of approximately $1 \mathrm{~mJ} /$ pulse at $10 \mathrm{~Hz}$.

conclusively that the excellent conversion efficiencies and relatively good operational lifetimes do not evolve with time. This is the first time (to our knowledge) that such results, very significant for future practical applications outside the laboratory, are being published for such hybrid dye-doped materials.

In addition, we also report the successful use of PM 605-doped hybrid sol-gel material for solid-state dye laser. Efficiency is comparable with previously reported samples of the same family: conversion efficiency up to $68 \%$, tunability in the $585-625 \mathrm{~nm}$ range (extending the spectral range of this "PM-doped" family in the red), and operational lifetime of over $10^{5}$ pulses in the millijoule regime.

These results, especially those concerning the pyrromethene family, are very promising and encouraging in terms of future applications in which solidstate dye-doped materials could well partially replace conventional liquid doped solutions.

This work was partially supported by the bilateral collaboration project 9073 between the Centre National de la Recherche Scientifique (France) and the National Center for Sciences and Technology (Vietnam).

\section{References}

1. D. Avnir, D. Levy, and R. Reisfeld, "The nature of the silica cage as reflected by spectral changes and enhanced photostability of trapped rhodamine 6G," J. Phys. Chem. 88, 59565959 (1984).

2. R. Reisfeld, D. Brusilovsky, M. Eyal, E. Miron, Z. Breustein, and J. Ivri, "A new solid-state tunable laser in the visible," Chem. Phys. Lett. 160, 43-44 (1989).

3. B. Dunn and J. I. Zink, "Optical properties of sol-gel glasses doped organic molecules," J. Mater. Chem. 1, 903-913 (1991).

4. R. E. Hermes, T. H. Allik, S. Chandra, and J. A. Hutchinson, "High efficiency pyrromethene doped solid-state dye laser," Appl. Phys. Lett. 63, 877-879 (1993).

5. M. D. Rhan, T. A. King, C. A. Capozzi, A. B. Seddon, "Characteristics of dye doped Ormosil laser," in Sol-Gel Optics III, J. D. Mackenzie, ed., Proc. SPIE 2288, 364-371 (1994).

6. B. Dunn, F. Nishida, K. Toda, J. Zin, T. Allik, S. Chandra, and J. A. Hutchinson, "Advances in dye doped sol-gel lasers," in New Materials for Advanced Solid-State Lasers, Mater. Res. Soc. Symp. Proc. 329, 267-277 (1994).

7. M. Faloss, M. Canva, P. Georges, A. Brun, F. Chaput, and J. P. Boilot, "Toward millions of laser pulses with pyrrometheneand perylene-doped xerogels," Appl. Opt. 36, 6760-6763 (1997).

8. M. Canva, B. Darracq, F. Chaput, K. Lahlil, F. Bentivegna, M. Brunel, M. Faloss, P. Georges, A. Brun, J. P. Boilot, and Y. Levy, "Functionalized dye-doped hybrid sol-gel materials for solid-state dye laser to nonlinear applications and organic photoreactivity," in Organic-Inorganic Hybrid Materials for Photonics, L. G. Hubert-Pfalzgraf and S. Najafi, eds., Proc. SPIE 3469, 164-173 (1998).
9. M. Fukuda, K. Komada, and K. Mito, "Perylene orange doped acrylic polymer for solid-state dye laser," Jpn. J. Appl. Phys. Lett. Part 2 40, L440-L442 (2001).

10. A. Costela, I. Garcia Moreno, J. M. Figuera, F. Amat Gueri, J. Barroso, and R. Sastre, "Solid-state dye laser based on Coumarin 540A-doped polymeric matrices," Opt. Commun. 130, 44-50 (1996).

11. A. Maslyukov, S. Sokolov, M. Kailova, K. Nyholm, and S. Popov, "Solid-state dye laser with modified poly(methyl methacrylate)-doped active elements," Appl. Opt. 34, 15161518 (1995).

12. A. Bergmann, W. Holzer, R. Stark, H. Gratz, A. Penzkofer, F. Amat Guerri, A. Costela, I. Garcia Moreno, and R. Sastre, "Photophysical characterization of pyrromethene dyes in solid matrices of acrylic copolymers," Chem. Phys. 271, 201-213 (2001).

13. S. S. Yap, T. Y. Tou, and S. W. Ng, "Laser emission from disodium fluorescein-doped poly(vinyl alcohol) films," Jpn. J. Appl. Phys. Part 1 39, 5855-5858 (2000).

14. Y. V. Kravchenko, A. A. Manenkov, G. A. Matushin, V. M. Mizin, D. P. Pacheco, and H. R. Aldag, "New high-efficiency pyrromethene-580 doped modified PMMA solid-state dye laser," in Solid State Lasers VI, R. Scheps, ed., Proc. SPIE 2986, 124-131 (1997)

15. K. S. Lam and D. Lo, "Lasing behavior of sol-gel silica doped with UV laser dye," Appl. Phys. B 66, 427-430 (1998).

16. M. D. Rahn and T. A. King, "High-performance solid-state dye laser based on Perylene-orange-doped polycom glass," J. Mod. Opt. 45, 1259-1267 (1998).

17. T. Suratwala, Z. Gardlund, K. Davidson, D. R. Uhlmann, S. Bonilla, and N. Peyghambarian, "Processing and photostability of Pyrromethene 567 polycerams," J. Sol-Gel Sci. Technol. 8, 953-958 (1997).

18. M. Canva, P. Georges, J. P. Perelgritz, A. Brun, F. Chaput, and J. P. Boilot, "Perylene- and pyrromethene-doped xerogel for a pulsed laser," Appl. Opt. 34, 428-431 (1995).

19. M. Faloss, M. Canva, P. Georges, A. Brun, F. Chaput, and J. P. Boilot, "Lasing performance of pyrromethene and perylene laser dyes in xerogel host," in Advanced Solid-State Laser, Vol. 1 of OSA Trends in Optics and Photonics Series (Optical Society of America, Washington, D.C., 1996), pp. 69-71.

20. M. Dubois, M. Canva, A. Brun, F. Chaput, and J. P. Boilot, "Photostability of dye molecules trapped in solid matrices," Appl. Opt. 35, 3193-3199 (1996).

21. B. Lebeau and C. Sanchez, "Sol-gel derived hybrid inorganicorganic nanocomposites for optics," Curr. Opin. Solid State Mater. Sci. 4, 11-23 (1999).

22. M. J. Cazeca, X.-L. Jiang, J. Kumar, and S. K. Tripathy, "Epoxy matrix for solid-state dye laser applications," Appl. Opt. 36, 4965-4968 (1997).

23. G. Jones, II, O. Klueva, S. Kumar, and D. Pacheco, "Photochemical and lasing properties of pyrromethene dyes," in Solid State Lasers X, R. Scheps, ed., Proc. SPIE 4267, 24-35 (2001).

24. M. Faloss, "Etude de laser à colorants solides et accordables préparés par procédé sol-gel,” Ph.D. Thesis (University of Paris, Paris, France, 1997).

25. M. S. Mackey and W. N. Sisk, "Photostability of pyrromethene 567 laser dye solutions via photomuminescence measurements," Dyes Pigm. 51, 79-85 (2001). 
26. A. J. Finlayson, N. Peters, P. V. Kolinsky, and M. R. W. Venner, "Flashlamp pumped solid-state dye laser incorporating pyrromethene 597," Appl. Phys. Lett. 75, 457-459 (1999).

27. M. Ahmad, M. D. Rahn, and T. A. King, "Singlet oxygen and dye-triplet-state quenching in solid-state dye lasers consisting of Pyrromethene 567-doped poly(methyl methacrylate)," Appl. Opt. 38, 6337-6342 (1999).

28. M. D. Rahn, T. A. King, A. A. Gorman, and I. Hamblett, "Photostability enhancement of Pyrromethene 567 and Perylene Orange in oxygen-free liquid and solid dye laser," Appl. Opt. 36, 5862-5871 (1997).

29. A. Costela, I. Garcia Moreno, R. Sastre, F. Lopez Arbeloa, T. Lopez Arbeloa, and I. Lopez Arbeloa, "Photophysical and lasing properties of pyrromethene 567 dye in solid poly(trifluomethyl methacrylate) matrices with different degrees of crosslinking," Appl. Phys. B 73, 19-24 (2001).

30. F. Lopez Arbeloa, T. Lopez Arbeloa, I. Lopez Arbeloa, I. Garcia
Moreno, A. Costela, F. Amat Gueri, and R. Sastre, "Photophysical and lasing properties of pyrromethene 567 dye in liquid solution. Environment effects," Chem. Phys. 236, 331341 (1998).

31. T. G. Pavlopoulos, "Photostability of some pyrromethene laser dyes," in Solid State Lasers VIII, R. Scheps, ed., Proc. SPIE 3613, 112-118 (1999).

32. M. V. Bondar and O. V. Przhonskaya, "Spectral-luminescence and lasing properties of the pyrromethene dye PM-567 in ethanol and in a polymer matrix," Quantum Electron. 28, 753-756 (1998).

33. H. Aldag, S. Dolotov, M. Koldunov, Y. Kravchenko, A. Manenkov, D. Pacheco, E. Ponomarenko, A. Reznichenko, G. Roskova, and T. Tsekhomskaya, "A microporous glasspolymer composite as a new material for solid-state dye lasers. II. Lasing properties," Quantum Electron. 30, 1055-1059 (2000). 